\title{
Prediction of electric consumption using multiple linear regression methods
}

Autores

Amelec Viloria, Hugo Hernandez-P, Omar Bonerge Pineda Lezama, Jesús Vargas

\begin{abstract}
In the new global and local scenario, the advent of intelligent distribution networks, or Smart Grids, allows the collection of data about the operational state of the electric network in real time. Based on this data availability, the consumption prediction becomes feasible and convenient in the short term, from a few hours to a week (temporary variables). The research proposes that the method used to present the temporary variables for a system to predict electrical consumption affects the results. To verify this hypothesis, different methods for representing these variables are considered, applied to the problem of predicting daily values of electricity consumption in the city of Bogota, Colombia.
\end{abstract}

Palabras clave

Energy consumption, Short term load forecasting, Variable selection, Linear regression. 